\title{
Studi Karakteristik Penataan Parkir Pada Jalan Mangunsarkoro Kabupaten Cianjur
}

\author{
${ }^{1}$ Yudi Sekaryadi , ${ }^{2}$ Devi Setiawan, ${ }^{3}$ Ryan reynaldi \\ Program Studi Teknik Sipil Fakultas Teknik Universitas Suryakancana \\ yudisekaryadi65@gmail.com,devift@unsur.ac.id
}

\begin{abstract}
Abstrak
Wilayah Kabupaten Cianjur merupakan daerah yang cukup strategis karena berbatasan dan dekat dengan kota-kota besar. Kabupaten Cianjur merupakan daerah yang sedang berkembang terutama di bidang perdagangan. Dengan berkembangnya di bidang perdagangan, maka jumlah penduduk di Cianjur semakin meningkat sesuai dengan kebutuhan akan kehidupan sehari-hari. Di jalan mangunsarkoro merupakan kawasan perdagangan yang dilengkapi dengan prasarana perpakiran yang memadai sehingga banyak pengunjung yang memanfaatkan badan jalan sebagai tempat parkir.

Penelitian ini menggunakan metode survai lapangan dengan melakukan pengamatan secara langsung, Pengamatan langsung dilakukan dengan pencatatan secara manual data masuk kendaraan dan keluar kendaraan Analisis penelitian menggunakan microsoft excel.

Dari analisis didapat Kebutuhan luas Ruang Parkir pada jalan mangunsarkoro adalah 688,5 $\mathrm{m}^{2}$ untuk sepeda motor sedangkan untuk mobil $1437 \mathrm{~m}^{2}$. Dan juga hasil kebutuhan ruang parkir yang di dapat yaitu untuk motor 454 ruang, untuk mobil di dapat 125 ruang.
\end{abstract}

Kata kunci : akumulasi,volume parkir, indeks parkir, durasi parkir, ruang parkir.

\section{PENDAHULUAN}

Wilayah Kabupaten Cianjur merupakan daerah yang cukup strategis karena berbatasan dan dekat dengan kota-kota besar. Kabupaten Cianjur merupakan daerah yang sedang berkembang terutama di bidang perdagangan. Dengan berkembangnya di bidang perdagangan, maka jumlah penduduk di Cianjur semakin meningkat sesuai dengan kebutuhan akan kehidupan seharihari. Dengan demikian banyaknya kios-kios sebagai tempat perdagangan yang dapat memenuhi kebutuhan penduduk di jalan mangunsarkoro yang memadai.

Dilihat dari karakteristiknya kios-kios yang terdapat di jalan mangunkarsoro umunya termasuk kios yang sudah cukup lama, karena disana kios ada yang memiliki tempat peragaan permanen (los) dan ada yang tidak memiliki toko maupun los (pedagang kaki lima).

Banyak kios yang dikunjungi oleh masyarakat di jalan mangunsarkoro ,berbagai macam barang sandang, pangan, obat-obatan dan lain-lain dijual di pasar tempat tersebut. Ada toko (kios) yang hanya menjual satu macam barang dan ada pula toko (kios) yang menjual berbagai macam barang. Sedangkan tempat peragaan permanen (los) diperuntukan bagi bahan pangan kebutuhan seharihari yang sifatnya tidak tahan lama, seperti sayursayuran, buah-buahan, ikan, daging, rempah- rempah, dan lain-lain. Di jalan mangunsarkoro tersebut dijumpai pula warung nasi dan warung kopi. Di jalan mangunsarkoro merupakan kawasan perdagangan yang dilengkapi dengan prasarana perpakiran yang memadai sehingga banyak pengunjung yang memanfaatkan badan jalan sebagai tempat parkir.

Di area tersebut banyak dipergunakan sebagai kawasan pertokoan, perkantoran, perbengkelan, perindustrian, dan pergudangan, sehingga di kawasan tersebut cukup ramai kegiatannya terutama pada pagi hari di mana banyak orang dengan aktivitas berkumpul.

Tujuan dari penelitian ini adalah untuk mengetahui karakteristik parkir yaitu akumulasi parkir, volume parkir, indeks parkir, dan durasi parkir di jalan mangunsarkorn dan mengetahui kebutuhan luas ruang dan fasilitas parkir jalan Mangunsarkoro berdasarkan standar parkir di jalan raya.

Lokasi penelitian ini terletak berada di J1. Mangunsarkoro, jalan raya by pass Kabupaten Cianjur. 


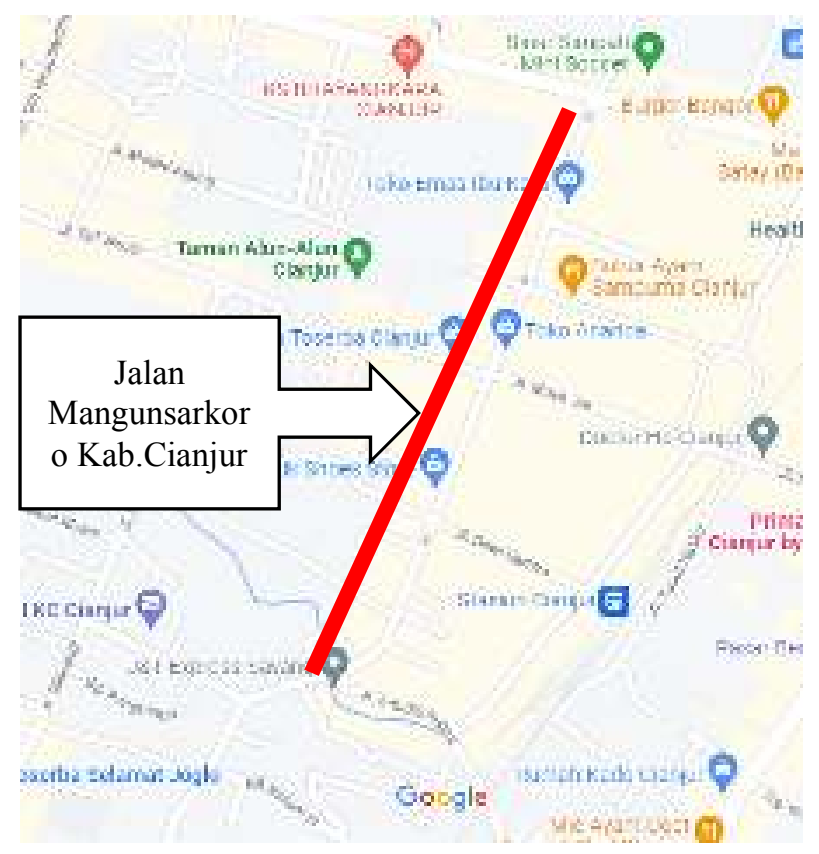

Gambar 1.Lokasi Penelitian Sumber : Google Maps

Tujuan penelitian ini untuk mengetahui karakteristik parkir yaitu akumulasi parkir, volume parkir, indeks parkir, dan durasi parkir di jalan mangunsarkoro. Dan untuk mengetahui kebutuhan luas ruang dan fasilitas parkir jalan Mangunsarkoro berdasarkan standar parkir menurut Direktorat Bina Sistem Lalu Lintas Angkutan Kota Direktor Jenderal Perhubungan Darat tentang Perencanaan dan Pengoperasian Fasilitas Parkir.

\section{TINJAUAN PUSTAKA}

\section{a. Pengertian Umum Parkir}

Parkir adalah keadaan tidak bergerak dari suatu kendaraan yang bersifat sementara (Direktorat Jendral Perhubungan Darat, 1996). Selain Pengertian di atas beberapa ahli memberikan definisinya tentang parkir, yaitu :

1. Parkir adalah keadaan tidak bergerak suatu kendaraan yang tidak bersifat sementara.

2. Berhenti adalah keadaan tidak bergerak suatu kendaraan untuk sementara dengan pengemudi tidak meninggalkan kendaraan.

3. Fasilitas parkir adalah lokasi yang ditentukan sebagai tempat pemberhentian kendaraan yang tidak bersifat sementara untuk melakukan kegiatan pada suatu kurun waktu.

4. Tempat parkir di badan jalan, (on street parking) adalah fasilitas parkir yang menggunakan tepi jalan.

5. Fasilitas parkir di luar badan jalan (off street parking) adalah fasilitas parkir kendaraan di luar tepi jalan umum yang dibuat khusus atau penunjang kegiatan yang dapat berupa tempat parkir dan/atau gedung parkir.

6. Jalan adalah tempat jalan yang diperuntukan bagi lalu lintas umum.

7. Satuan ruang parkir (SRP) adalah ukuran luas efektif untuk meletakkan kendaraan (mobil penumpang, bus/truk, atau sepeda motor), termasuk ruang bebas dan lebar buka pintu. Untuk hal-hal tertentu bila tanpa penjelasan, SRP adalah SRP untuk mobil penumpang.

8. Jalur sirkulasi adalah tempat, yang digunakan untuk pergerakan kendaraan yang masuk dan keluar dari fasilitas parkir.

9. Jalur gang merupakan jalur antara dua deretan ruang parkir yang berdekatan. 10.Kawasan parkir adalah kawasan atau areal yang memanfaatkan badan jalan sebagai fasilitas parkir dan terdapat pengendalian parkir melalui pintu masuk.

Berdasarkan dari definisi-definisi di atas maka dapat ditarik kesimpulan bahwa parkir adalah suatu keadaan tidak bergerak sutau kendaraan bermotor atau tidak bermotor yang dapat merupakan awal dari perjalanan dengan jangka waktu tertentu sesuai dengan keadaan dan kebutuhannya yang membutuhkan suatu areal sebagai tempat pemberhentian yang diselenggarakan baik oleh pemerintah maupun pihak lain yang dapat berupa perorangan maupun badan usaha.

\section{b. Penentuan Kebutuhan Parkir}

1) Jenis peruntukan kebutuhan parkir sebagai berikut

a. Kegiatan parkir yang tetap

1) Pusat pedagangan

2) Pusat perkantoran swasta atau pemerintahan

3) Pusat pedagangan eceran atau pasar swalayan

4) Pasar

5) Sekolah

6) Tempat rekreasi

7) Hotel dan tempat penginapan

8) Rumah sakit

b. Kegiatan parkir yang bersifat sementara

1) Bioskop

2) Tempat pertunjukan

3) Tempat pertandingan olahraga

4) Rumah ibadah.

2) Ukuran kebutuhan ruang parkir pada pusat kegiatan ditentukan sebagai berikut: 
1) Kegiatan parkir yang tetap

Tabel 1. Pusat perdagangan

\begin{tabular}{|l|l|l|l|l|l|l|l|l|}
\hline Luas Areal Total $\left(100 \mathrm{~m}^{2}\right)$ & 10 & 20 & 50 & 100 & 500 & 1000 & 1500 & 2000 \\
\hline Kebutuhan (SRP) & 59 & 67 & 88 & 125 & 415 & 777 & 1140 & 1502 \\
\hline
\end{tabular}

Tabel 2. Pusat perkantoran

\begin{tabular}{|l|l|l|l|l|l|l|l|l|l|l|}
\hline \multicolumn{2}{|l|}{ jumlah karyawan } & 1000 & 1250 & 1500 & 1750 & 2000 & 2500 & 3000 & 4000 & 5000 \\
\hline \multirow{2}{*}{$\begin{array}{l}\text { kebutuhan } \\
\text { (SRP) }\end{array}$} & administrasi & 235 & 236 & 237 & 238 & 239 & 240 & 242 & 246 & 249 \\
\cline { 2 - 10 } & $\begin{array}{l}\text { pelayanan } \\
\text { umum }\end{array}$ & 288 & 289 & 290 & 291 & 291 & 293 & 293 & 298 & 302 \\
\hline
\end{tabular}

Tabel 3. Pasar swalayan

\begin{tabular}{|c|c|c|c|c|c|c|c|c|c|}
\hline Luas Areal Total $\left(100 \mathrm{~m}^{2}\right)$ & 50 & 75 & 100 & 150 & 200 & 300 & 400 & 500 & 1000 \\
\hline Kebutuhan (SRP) & 225 & 250 & 270 & 310 & 350 & 440 & 520 & 600 & 1050 \\
\hline
\end{tabular}

Tabel 4. Pasar

\begin{tabular}{|c|c|c|c|c|c|c|c|c|c|}
\hline Luas Areal Total $\left(100 \mathrm{~m}^{2}\right)$ & 40 & 50 & 75 & 100 & 200 & 300 & 400 & 500 & 1000 \\
\hline Kebutuhan (SRP) & 160 & 185 & 240 & 300 & 520 & 750 & 970 & 1200 & 2300 \\
\hline
\end{tabular}

Tabel 5. Sekolah/perguruan tinggi

\begin{tabular}{|c|c|c|c|c|c|c|c|c|c|c|}
\hline $\begin{array}{c}\text { jumlah } \\
\text { mahasiswa } \\
\text { (orang) }\end{array}$ & 3000 & 4000 & 5000 & 6000 & 7000 & 8000 & 9000 & 10000 & 11000 & 12000 \\
\hline $\begin{array}{c}\text { Kebutuhan } \\
\text { (SRP) }\end{array}$ & 60 & 80 & 100 & 120 & 140 & 160 & 180 & 200 & 220 & 240 \\
\hline
\end{tabular}

Tabel 6. Tempat rekreasi

\begin{tabular}{|c|c|c|c|c|c|c|c|c|c|}
\hline Luas Areal Total $\left(100 \mathrm{~m}^{2}\right)$ & 50 & 100 & 150 & 200 & 400 & 800 & 1600 & 3200 & 6400 \\
\hline Kebutuhan $(\mathrm{SRP})$ & 103 & 109 & 115 & 122 & 146 & 196 & 295 & 494 & 892 \\
\hline
\end{tabular}

Tabel 7. Hotel dan tempat penginapan

\begin{tabular}{|c|c|c|c|c|c|c|c|c|c|c|}
\hline $\begin{array}{c}\text { Jumlah } \\
\text { Kamar } \\
\text { (buah) }\end{array}$ & & 100 & 150 & 200 & 250 & 350 & 400 & 550 & 550 & 600 \\
\hline \multirow{4}{*}{$\begin{array}{c}\text { Tarip } \\
\text { standart }\end{array}$} & $100-150$ & 300 & 450 & 476 & 477 & 480 & 491 & 484 & 495 & 487 \\
\cline { 2 - 11 } & $150-200$ & 300 & 450 & 600 & 798 & 799 & 800 & 803 & 804 & 806 \\
\cline { 2 - 12 } & $200-250$ & 300 & 450 & 600 & 900 & 1050 & 1119 & 1122 & 1124 & 1425 \\
\hline
\end{tabular}


Tabel 8. Rumah sakit

\begin{tabular}{|c|c|c|c|c|c|c|c|c|c|}
\hline $\begin{array}{c}\text { jumlah tempat tidur } \\
\text { (buah) }\end{array}$ & 50 & 75 & 100 & 150 & 200 & 300 & 400 & 500 & 1000 \\
\hline Kebutuhan (SRP) & 97 & 100 & 104 & 111 & 118 & 132 & 146 & 160 & 230 \\
\hline
\end{tabular}

2) Kegiatan parkir yang bersifat sementara

Tabel 9. Bioskop

\begin{tabular}{|c|c|c|c|c|c|c|c|c|c|}
\hline $\begin{array}{c}\text { jumlah tempat duduk } \\
\text { (buah) }\end{array}$ & 300 & 400 & 500 & 600 & 700 & 800 & 900 & 1000 & 1000 \\
\hline Kebutuhan (SRP) & 198 & 202 & 206 & 210 & 214 & 218 & 222 & 227 & 230 \\
\hline
\end{tabular}

Tabel 10. Tempat pertandingan olah raga

\begin{tabular}{|c|c|c|c|c|c|c|c|c|c|}
\hline $\begin{array}{c}\text { jumlah tempat tidur } \\
\text { (buah) }\end{array}$ & 4000 & 5000 & 6000 & 7000 & 8000 & 9000 & 10000 & 15000 & 1000 \\
\hline Kebutuhan (SRP) & 235 & 290 & 340 & 390 & 440 & 490 & 540 & 790 & 230 \\
\hline
\end{tabular}

\section{c. Penentuan Satuan Ruang Parkir (SRP)}

Penentuan satuan ruang parkir (SRP) didasarkan atas hal berikut.

1) Dimensi kendaraan standar untuk mobil penumpang.

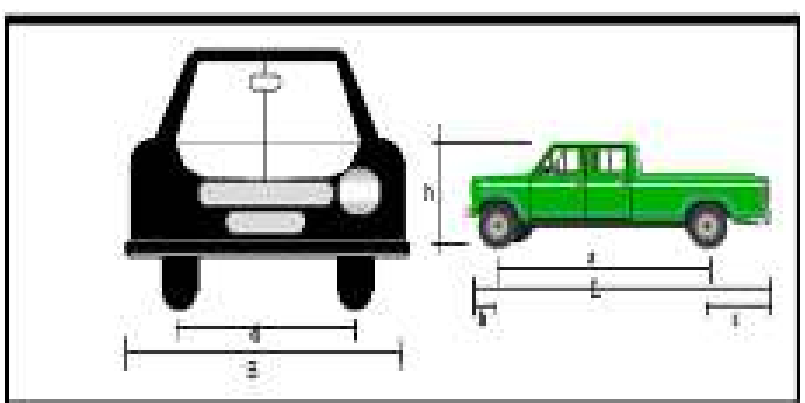

Gambar 2. Dimensi Kendaraan Standar untuk Mobil Penumpang

Keterangan :

$\mathrm{a}=$ jarak gandar

$\mathrm{b}=$ depan tergantung

$\mathrm{c}=$ belakang tergantung

$\mathrm{d}=$ lebar

$\mathrm{h}=$ tinggi total

$\mathrm{B}=$ lebar total

$\mathrm{L}=$ panjang total

2) Ruang bebas kendaraan parkir

Ruang bebas kendaraan parkir diberikan pada arah lateral dan longitudinal kendaraan. Ruang bebas arah lateral ditetapkan pada saat posisi pintu kendaraan dibuka, yang diukur dari ujung terluar pintu ke badan kendaraan parkir yang ada di sampingnya. Ruang bebas ini diberikan agar tidak terjadi benturan antara pintu kendaraan dan kendaraan yang parkir di sampingnya pada saat penumpang turun dari kendaraan. Ruang bebas arah memanjang diberikan di depan kendaraan untuk menghindari benturan dengan dinding atau kendaraan yang lewat jalur gang (aisle). Jarak bebas arah lateral diambil sebesar $5 \mathrm{~cm}$ dan jarak bebas arah longitudinal sebesar $30 \mathrm{~cm}$.

3) Lebar bukaan pintu kendaraan

Ukuran lebar bukaan pintu merupakan fungsi karakteristik pemakai kendaraan yang memanfaatkan fasilitas parkir. Sebagai contoh, lebar bukaan pintu kendaraan karyawan kantor akan berbeda dengan lebar bukaan pintu kendaraan pengunjung pusat kegiatan perbelanjaan. Dalam hal ini, karakteristik pengguna kendaraan yang memanfaatkan fasilitas parkir dipilih menjadi tiga seperti dalam Tabel berikut: 
Tabel 11. Lebar Bukaan Pintu Kendaraan

\begin{tabular}{|c|c|c|}
\hline $\begin{array}{l}\text { Jenis Bukaan } \\
\text { Pintu }\end{array}$ & $\begin{array}{ll}\text { Pengguna } & \text { dan/atau } \\
\text { Peruntukan } & \text { Fasilitas } \\
\text { Parkir } & \\
\end{array}$ & Gol \\
\hline & $\begin{array}{l}\text { Karyawan/pekerja } \\
\text { kantor }\end{array}$ & \\
\hline $\begin{array}{l}\text { Pintu } \\
\text { depan/belaka } \\
\text { ng terbuka }\end{array}$ & $\begin{array}{l}\text { Tamu/pengunjung } \\
\text { pusat } \\
\text { kegiatan perkantoran, } \\
\text { perdadagangan,pemer } \\
\text { intahan, } \\
\text { universitas }\end{array}$ & I \\
\hline $\begin{array}{l}\text { Pintu } \\
\text { depan/belaka } \\
\text { ng terbuka } \\
\text { penuh } 75 \mathrm{~cm}\end{array}$ & $\begin{array}{l}\text { Pengunjung tempat } \\
\text { olahraga, pusat } \\
\text { hiburan/rekreasi, } \\
\text { hotel, pusat } \\
\text { perdagangan } \\
\text { eceran/swalayan, } \\
\text { rumah sakit, bioskop }\end{array}$ & II \\
\hline $\begin{array}{l}\text { Pintu depan } \\
\text { terbuka penuh } \\
\text { dan } \\
\text { ditambah } \\
\text { untuk } \\
\text { pergerakan } \\
\text { kursi } \\
\text { roda }\end{array}$ & Orang cacat & III \\
\hline
\end{tabular}

Berdasarkan Butir 1 dan 2, penentuan satuan ruang parkir (SRP) dibagi atas tiga jenis kendaraan dan berdasarkan butir 3, penentuan SRP untuk mobil penumpang diklasifikasikan menjadi tiga golongan, seperti pada Tabel

Tabel 12. Penentuan Satuan Ruang Parkir (SRP)

\begin{tabular}{ll}
\hline Jenis Kendaraan Satuan & $\begin{array}{l}\text { Satuan } \\
\text { Parkir }(\mathrm{m} 2)\end{array}$ \\
Ruang Parkir $(\mathrm{m} 2)$ & Ruang \\
\hline $\begin{array}{l}\text { 1. a. Mobil penumpang } \\
\text { untuk golongan I }\end{array}$ & $2,30 \times 5,0$ \\
\hline $\begin{array}{l}\text { b. Mobil penumpang untuk } \\
\text { golongan II }\end{array}$ & $2,50 \times 5,0$ \\
\hline $\begin{array}{l}\text { c. Mobil penumpang untuk } \\
\text { golongan III }\end{array}$ & $3,00 \times 5,0$ \\
\hline 2. Bus/Truk & $3,40 \times 12,5$ \\
\hline 3. Sepeda motor & $0,75 \times 2,0$ \\
\hline
\end{tabular}

Besar satuan ruang parkir untuk tiap jenis kendaraan adalah sebagai berikut. a. Satuan Ruang Parkir untuk Mobil Penumpang

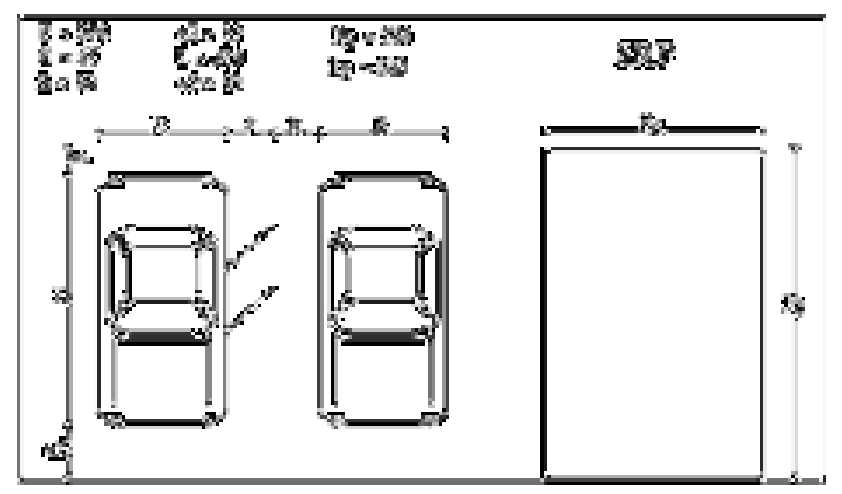

Gambar 3. Satuan Ruang Parkir (SRP) untuk Mobil Penumpang

Keterangan :

$\mathrm{B}=$ lebar total kendaraan

$\mathrm{L}=$ panjang total kendaraan

$\mathrm{O}=$ lebar bukaan pintu

a1, a 2 = jarak bebas arah longitudinal

b. Satuan Ruang Parkir untuk Sepeda Motor

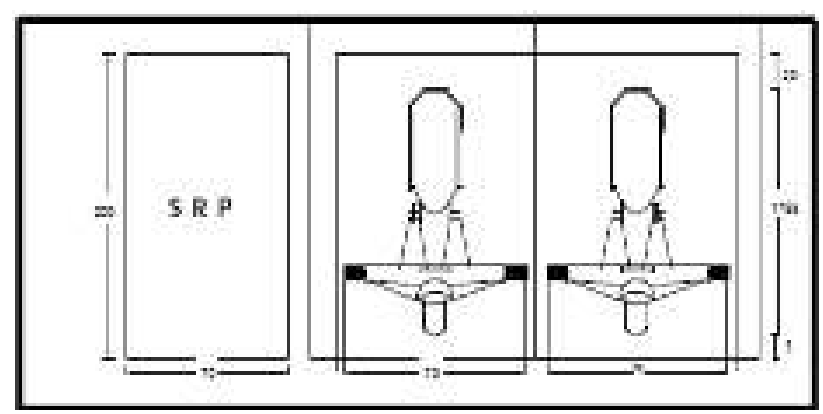

Gambar 4. satuan ruang parkir untuk sepeda motor

\section{d. Desain Parkir di Badan Jalan}

1. Penentuan Sudut Parkir

Sudut parkir yang akan digunakan umumnya ditentukan oleh:

- lebar jalan;

- volume lalu lintas pada jalan bersangkutan;

- karakteristik kecepatan;

- dimensi kendaraan;

- sifat peruntukkan lahan sekitarnya dan peranan jalan yang bersangkutan. 
2. Pola Parkir

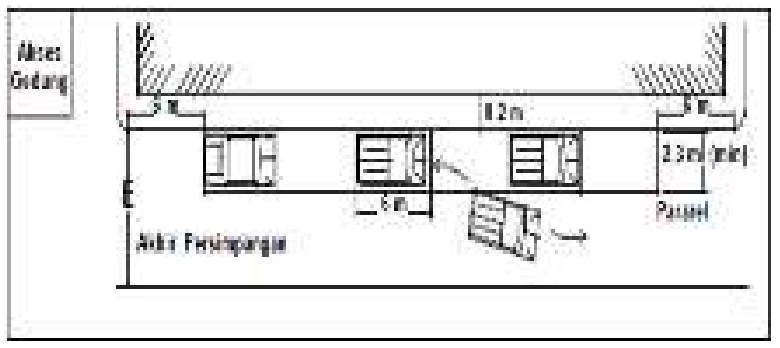

Gambar 5. pola parkir pada daerah datar

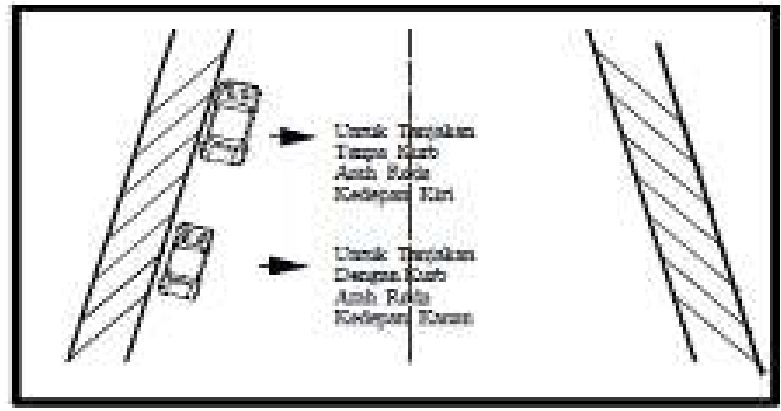

Gambar 6 . pola parkir pada daerah tanjakan

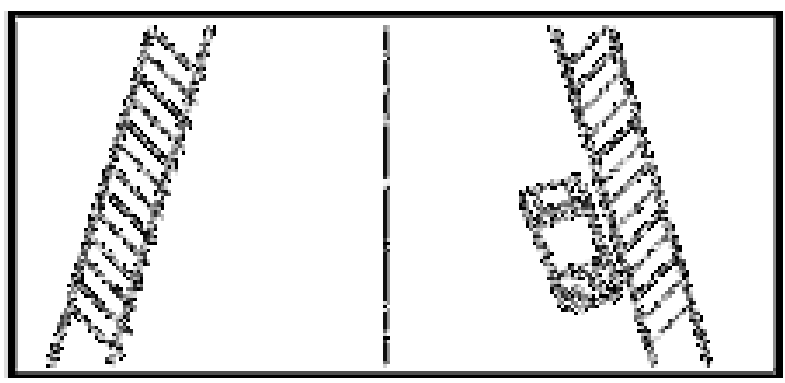

Gambar 7. pola parkir pada daerah turunan

b. Pola parkir menyudut :

1. Lebar ruang parkir, ruang parkir efektif, dan ruang manuver berlaku untuk jalan kolektor dan lokal

2. Lebar ruang parkir, ruang parkir efektif, dan ruang manuver berbedam berdasarkan besar sudut berikut ini.

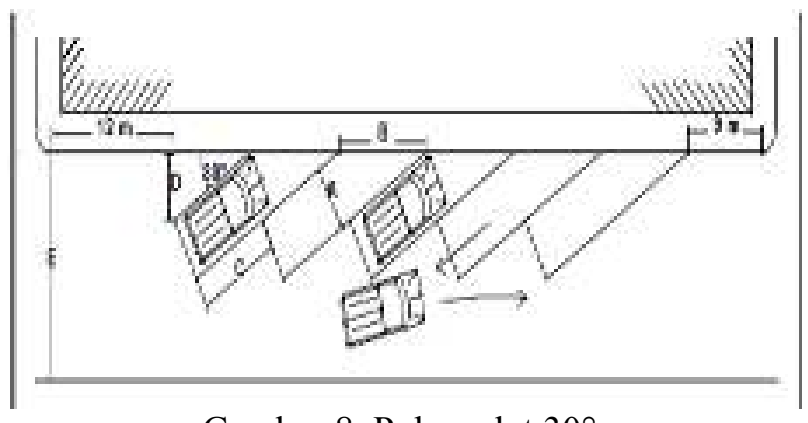

Gambar 8. Pola sudut $30^{\circ}$

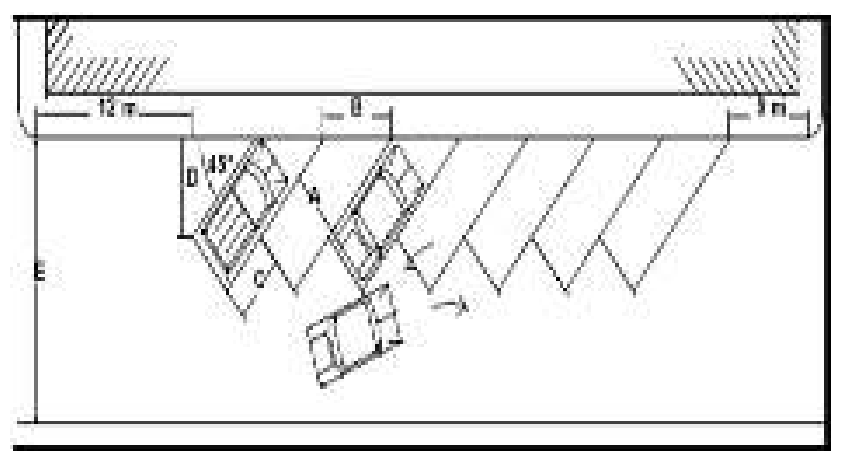

Gambar 9. Pola sudut $45^{\circ}$

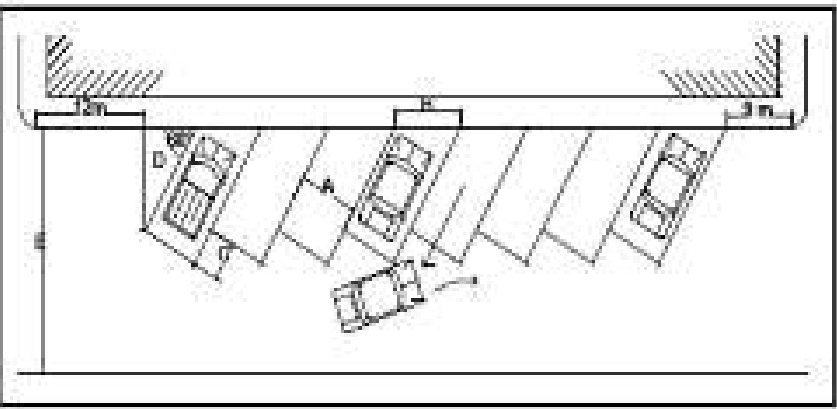

Gambar 10. Pola sudut $60^{\circ}$

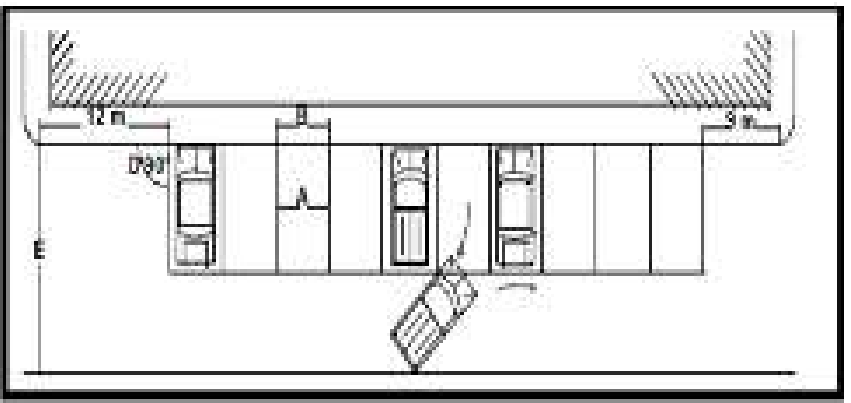

Gambar 11. Pola sudut $90^{\circ}$

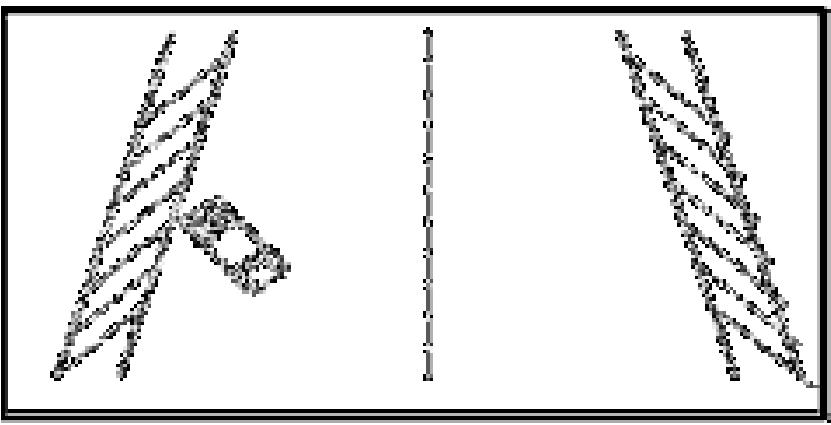

Gambar 12. pada daerah tanjakan 


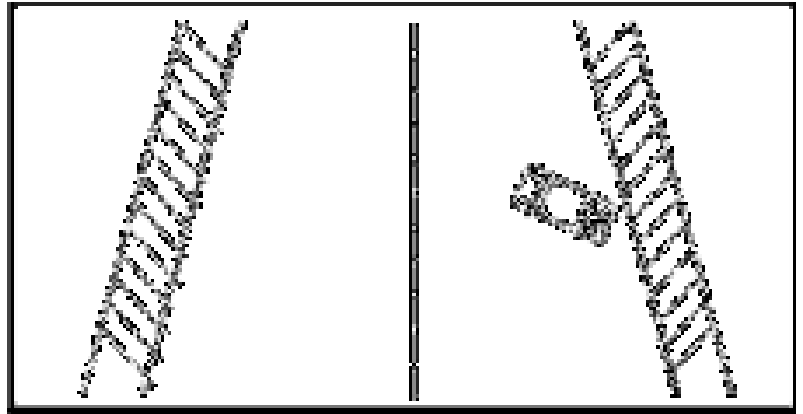

Gambar 13. pada daerah turunan

3. Larangan Parkir

a. Sepanjang 6 meter sebelum dan sesudah tempat penyeberangan pejalan kaki atau tempat penyeberangan sepeda yang telah ditentukan

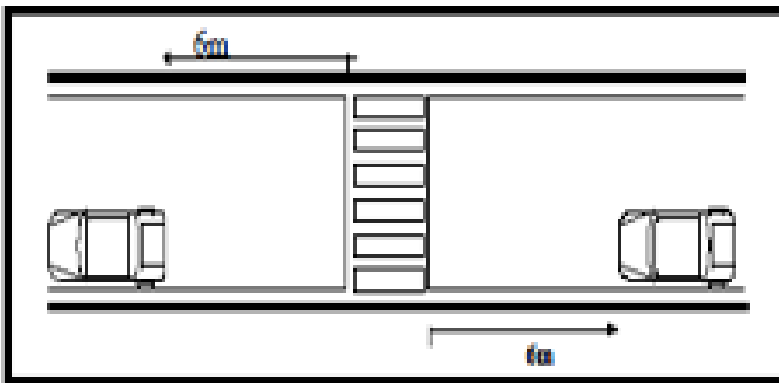

Gambar 14. Larangan parkir sepanjang $6 \mathrm{~m}$

b. Sepanjang 25 meter sebelum dan sesudah tikungan tajam dengan radius kurang dari $500 \mathrm{~m}$

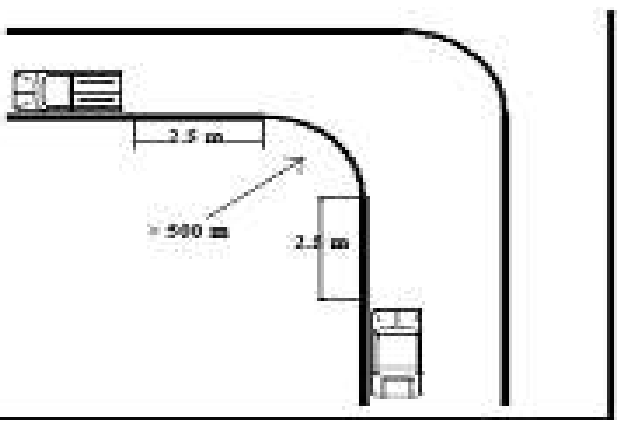

Gambar 15. Larangan parkir sepanjang $25 \mathrm{~m}$

c. Sepanjang 50 meter sebelum dan sesudah jembatan

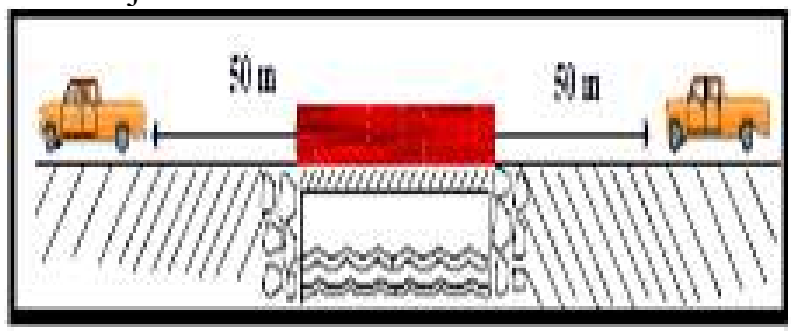

Gambar 16. Larangan parkir sepanjang $50 \mathrm{~m}$ d. Sepanjang 100 meter sebelum dan sesudah perlintasan sebidang

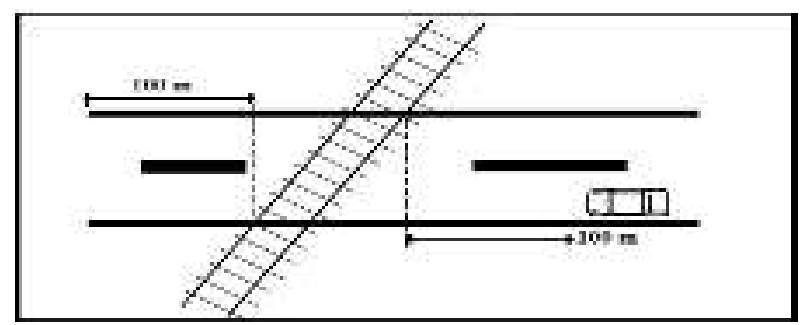

Gambar 17. Larangan parkir sepanjang $100 \mathrm{~m}$ sebelum dan sesudah perlintasan sebidang

e. Sepanjang 100 meter sebelum dan sesudah perlintasan sebidang

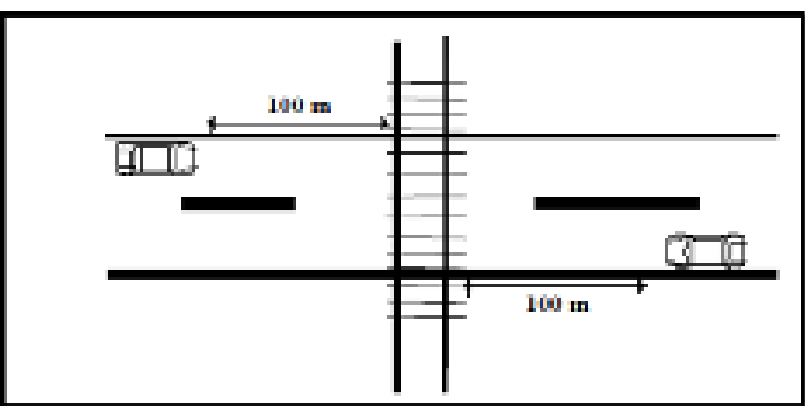

Gambar 18. Larangan parkir sepanjang $100 \mathrm{~m}$ sebelum dan sesudah perlintasan sebidang

f. Sepanjang 25 meter sebelum dan sesudah persimpangan

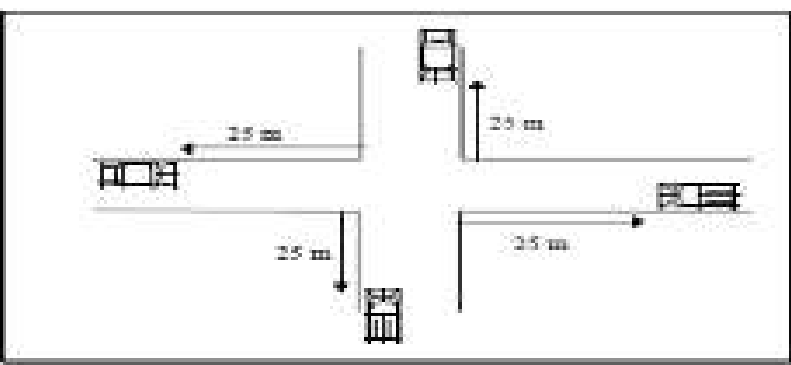

Gambar 19. Larangan parkir sepanjang 25 meter sebelum dan sesudah persimpangan

g. Sepanjang 6 meter sebelum dan sesudah akses bangunan gedung

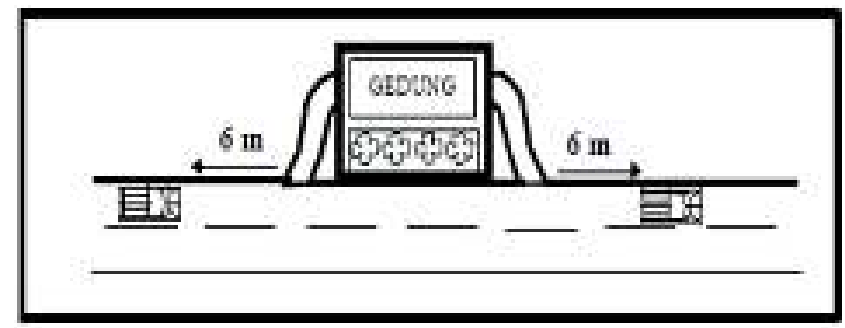

Gambar 20. Larangan parkir sepanjang 6 meter sebelum dan sesudah akses bangunan gedung 
h. Sepanjang 6 meter sebelum dan sesudah keran pemadam kebakaran atau sumber air sejenis

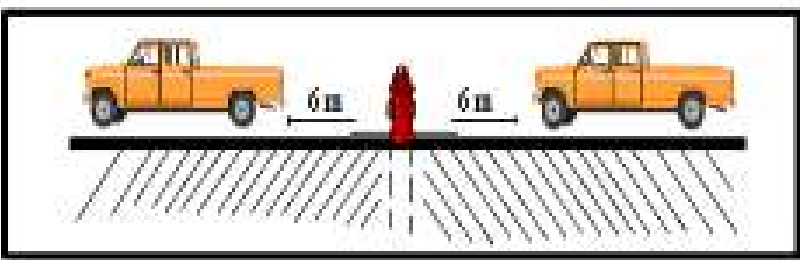

Gambar 21. Larangan parkir sepanjang 6 meter sebelum dan sesudah keran pemadam kebakaran

i. Sepanjang tidak menimbulkan kemacetan dan menimbulkan bahaya

\section{e. Pengoperasian Parkir}

Pengopersian parkir harus berjalan secara sistematis supaya fasilitas parkir dapat berjalan dengan tertib. Pengoperasian parkir terdiri dari pengorganisasian,penetapan tiap tarip dan tata cara parkir.

\section{METODOLOGI}

Pada penelitian ini kendaraan yang di teliti adalah mobil, dan motor yang memasuki jalan mangunsarkoro. Dengan panjang ruas jalan yaitu $715 \mathrm{~m}$. Penelitian dilaksanakan pada tanggal 11 Maret 2019 pada hari senin dan 12 maret pada hari minggu. Kedua hari itu diambil karena dilihat pada hari jam kerja dan libur. Waktu penelitian dimulai jam 07.00-17.00 WIB. Alat yang digunakan adalah sebagai berikut Lembar survey dan alat tulis, Alat penunjuk waktu, seperti arloji atau handphone.

Lokasi Penelitian berada di jalan mangun sarkoro sampai dengan toko lili.

\section{a. Tahapan Pelaksanaan Penelitian}

Tahapan keseluruhan pelaksanaan Penelitian dapat digambarkan dalam flowchart berikut:

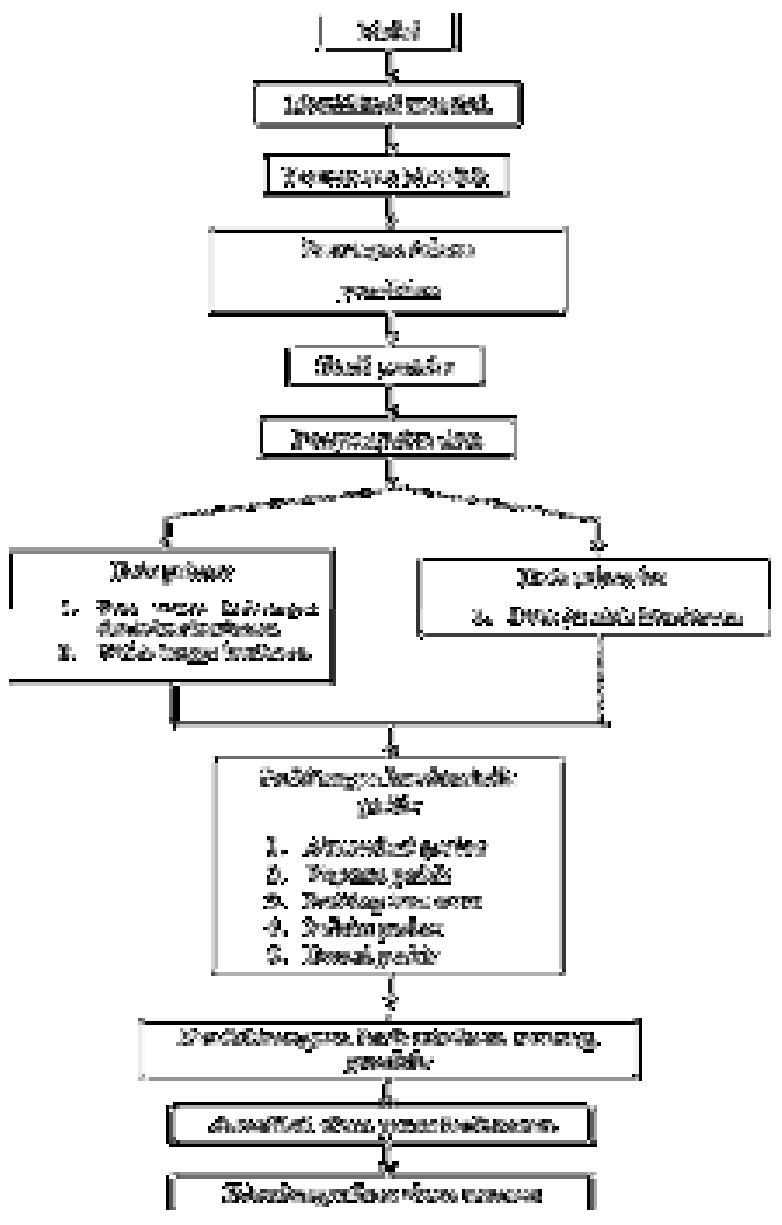

Gambar 21. Flowchart Pelaksanaan Penelitian

\section{b. Metode Pengumpulan Data}

1. Data Primer

Data primer merupakan data yang dibuat oleh peneliti untuk maksud khusus menyelesaikan permasalahan yang sedang ditanganinya. Data dikumpulkan sendiri oleh peneliti langsung dari sumber pertama atau tempat objek penelitian dilakukan. Data primer disini peneliti memperoleh secara langsung dari objek yang diteliti secara langsung melalui survei lapangan yang berupa :

- Data waktu kedatangan dan keluar kendaraan

- Waktu tunggu kendaraan data jumlah kendaraan

2. Survey

Surveyor adalah orang-orang yang diberi tugas untuk melakukan pengamatan langsung dan melakukan pencatatan data di lapangan. Surveyor sebelum menjalankan tugasnya diberikan pengarahan tentang teknis di lapangan serta lokasi dimana surveyor menjalankan tugas. Penelitian menggunakan tenaga surveyor kurang lebih sebanyak 3 orang yang ditempat pada titik lokasi yang sudah ditentukan. 


\section{Pencatatan Data}

Langkah pertama adalah menyamakan arloji ataupun alat pencatat waktu yang sejenis. Selanjutnya proses pencatatan data dapat dijelaskan sebagai berikut :

Langkah-langkah survai yang dilakukan meliputi :

a. Mendistribusikan secara jelas surveyor pada tit ik-titik lokasi pengamatan.

b. Kendaraan yang sudah ada di area depan pertokoan yang datang sebelum waktu pengamatan dicatat sebagai kendaraan yang parkir.

c. Setiap kendaraan yang melewati pintu masuk dicatat oleh surveyor berupa waktu datang, dan jenis kendaraan. Bila tidak memungkinkan mencatat semua variabel diatas karena frekuensi kendaraan yang padat maka diutamakan mencatat data waktu.

\section{c. Pengolahan Data}

Setelah pengambilan data selesai dan dilakukan pengumpulan, diatur sesuai tanggal dan tempat. Langkah-langkah analisis data sebagai berikut :

1. Menghitung akumulasi parkir.

2. Waktu interval yang dipakai adalah satu jam, dalam waktu itu dihitung jumlah kendaraan yang masuk dan keluar yang selanjutnya dibuat grafik sebagai penggambaran akumulasi parkir dalam periode waktu tertentu.

3. Menghitung volume parkir

4. Tingkat pergantian parkir (parking turnover).
5. Hasil perhitungan akumulasi parkir dan data ruang parkir yang tersedia digunakan untuk menghitung indeks parkir.

6. Durasi parkir dihitung.

7. Data yang dipakai adalah data waktu parkir.

\section{PEMBAHASAN}

Survey lapangan sudah dilaksanakan untuk motor tanggal 10 Maret 2019 pada hari minggu dan 11 maret, hari senin, untuk mobil survey dilaksanakan pada 17 maret pada hari minggu dan 18 maret pada hari senin. Kedua hari itu diambil karena dilihat pada hari jam kerja dan libur. Waktu penelitian dimulai jam 07.00-17.00 WIB. Secara umum penelitian berjalan dengan lancar.

Secara teknis di lapangan penelitian yang dilakukan di Jalan Mangunsarkoro. Dengan area yang sering padat dengan kendaraan yang parkir dan banyak kendaraan yang melintas di area tersebut. Oleh karena itu, dalam analisis dan pembahasan penelitian ini diklasifikasikan sesuai dengan area parkir tersebut.

\section{a. Akumulasi Parkir}

Akumulasi parkir dalam perhitungannya menggunakan persamaan 2.1 Perhitungan diklasifikasikan menurut arah kendaraan tersebut. Contoh perhitungan akumulasi parkir sebagai berikut : Pada periode waktu 07.00-17.00 WIB hari Senin dan hari Minggu

Tabel 13. Perhitungan Akumulasi Kendaraan Motor

\begin{tabular}{ccccccc}
\hline \multirow{2}{*}{ Waktu } & \multicolumn{3}{c}{ Hari Pertama (Senin) } & \multicolumn{3}{c}{ Hari Kedua (Minggu) } \\
\cline { 2 - 7 } & Masuk & Keluar & Akumulasi & Masuk & Keluar & Akumulasi \\
\cline { 2 - 7 } & A & B & A-B & A & B & A-B \\
\hline $07.00-08.00$ & 218 & 22 & 196 & 253 & 36 & 217 \\
\hline $08.00-09.00$ & 304 & 19 & 285 & 383 & 27 & 356 \\
\hline $09.00-10.00$ & 337 & 16 & 321 & 366 & 22 & 344 \\
\hline $10.00-11.00$ & 415 & 22 & 393 & 487 & 32 & 455 \\
\hline $11.00-12.00$ & 459 & 18 & 441 & 487 & 28 & 459 \\
\hline $12.00-13.00$ & 454 & 27 & 427 & 483 & 42 & 441 \\
\hline $13.00-14.00$ & 440 & 25 & 415 & 463 & 25 & 438 \\
\hline $14.00-15.00$ & 390 & 14 & 376 & 454 & 34 & 420 \\
\hline $15.00-16.00$ & 249 & 34 & 215 & 257 & 33 & 224 \\
\hline $16.00-17.00$ & 176 & 44 & 132 & 209 & 42 & 167 \\
\hline JUMLAH & 3442 & 241 & 3201 & 3842 & 321 & 3521 \\
\hline
\end{tabular}


Tabel 14. Perhitungan akumulasi mobil

\begin{tabular}{ccccccc}
\hline \multirow{2}{*}{ Waktu } & \multicolumn{3}{c}{ Hari Pertama (Senin) } & \multicolumn{3}{c}{ Hari Kedua (Minggu) } \\
\cline { 2 - 7 } & Masuk & Keluar & Akumulasi & Masuk & Keluar & Akumulasi \\
\cline { 2 - 7 } & $\mathrm{A}$ & $\mathrm{B}$ & $\mathrm{A}-\mathrm{B}$ & $\mathrm{A}$ & $\mathrm{B}$ & $\mathrm{A}-\mathrm{B}$ \\
\hline $07.00-08.00$ & 51 & 8 & 43 & 61 & 5 & 56 \\
\hline $08.00-09.00$ & 75 & 6 & 69 & 81 & 9 & 72 \\
\hline $09.00-10.00$ & 93 & 5 & 88 & 100 & 7 & 93 \\
\hline $10.00-11.00$ & 105 & 8 & 97 & 109 & 6 & 103 \\
\hline $11.00-12.00$ & 111 & 5 & 106 & 120 & 5 & 115 \\
\hline $12.00-13.00$ & 99 & 6 & 93 & 112 & 8 & 104 \\
\hline $13.00-14.00$ & 91 & 9 & 82 & 100 & 7 & 93 \\
\hline $14.00-15.00$ & 76 & 11 & 65 & 98 & 14 & 84 \\
\hline $15.00-16.00$ & 67 & 15 & 52 & 96 & 19 & 77 \\
\hline $16.00-17.00$ & 63 & 18 & 45 & 80 & 22 & 58 \\
\hline JUMLAH & 831 & 91 & 740 & 957 & 102 & 855 \\
\hline
\end{tabular}

\section{b. Volume Parkir}

Volume parkir dihitung dengan menjumlahkan kendaraan yang menggunakan area parkir pada jam pengamatan.

Tabel 13. volume parkir kendaraan

\begin{tabular}{|c|c|c|}
\hline Kendaraan & Senin & Minggu \\
\hline Motor & 3442 & 3842 \\
\hline Mobil & 831 & 957 \\
\hline
\end{tabular}

Volume parkir kendaraan Jalan Mangunsarkoro tertinggi berdasar Tabel 4.3 adalah pada hari minggu 3805 motor/hari sedangkan untuk mobil pada hari minggu $1232 \mathrm{mobil} /$ hari. Volume parker hari minggu lebih tinggi kemungkinan disebabkan karena adanya tempat rekreasi baru yang dibangun oleh pemerintah KAB.Cianjur yaitu Bomero city walk dan alun-alun Cianjur.

\section{c. Parking Turnover (Pergantian Parkir)}

- Perhitungan pergantian parkir $\mathrm{Pp}=(\mathrm{Vp}: \mathrm{Rp})$

Dengan :

$\mathrm{Pp}=$ Pergantian parkir (kendaraan/hari/SRP)

$\mathrm{Vp}=$ Volume parkir (kendaraanhari)

$\mathrm{Rp}=$ Ruang parkir (SRP)

- Untuk kendaraan motor pada hari senin $\mathrm{Pp}=(3442: 450)$

$$
=7,6 \sim 8
$$

- Untuk kendaraan bermotor pada hari minggu

$$
\begin{aligned}
\mathrm{Pp} & =(3842: 450) \\
& =8,5 \sim 9
\end{aligned}
$$

- Untuk mobil pada hari senin

$$
\mathrm{Pp}=(831: 100)
$$$$
=8
$$

- Untuk mobil pada hari minggu

$\mathrm{Pp}=(1232: 100)$

$$
=9
$$

Berdasar hasil perhitungan menunjukkan bahwa tingkat pergantian parkir jalan mangunsarkoro untuk motor pada hari senin sebesar 8 motor/hari/ruang dan pada hari minggu sebesar 9 motor/hari/ruang , dan untuk mobil pada hari senin $7 \mathrm{mobil} /$ hari/ruang untuk hari minggu sebesar 8 mobil /hari/ruang . Angka pergantian parkir menunjukkan bahwa selama periode waktu 10 jam penelitian (pukul 07.00-17.00.

\section{d. Indeks Parkir}

Berdasarkan perhitungan Tabel 14 indeks parkir rata-rata sebesar $98 \%$ pada hari senin dan pada hari minggu indeks parkir rata-rata sebesar 102,00\%. Nilai ratarata indeks parkir kurang dari $100 \%$ itu artinya bahwa petak parkir di areal hampir penuh terutama pada hari minggu. Rata-rata indeks parkir pada hari minggu lebih tinggi dibandingkan pada hari senin, hal itu disebabkan akumulasi parkir pada hari minggu rata-rata lebih besar. Sedangkan tingginya akumulasi parkir kemungkinan disebabkan tingginya mayoritas masyarakat yang keluar pada hari libur pekan 
Tabel 14. Indeks Parkir Motor

\begin{tabular}{lcccccc}
\hline & \multicolumn{3}{c}{ hari senin } & \multicolumn{3}{c}{ hari minggu } \\
\cline { 2 - 7 } waktu & Akumulasi & Petak Parkir & Indeks(\%) & Akumulasi & $\begin{array}{c}\text { Petak } \\
\text { Parkir }\end{array}$ & Indeks(\%) \\
\cline { 2 - 7 } & $\mathrm{A}$ & $\mathrm{B}$ & $\mathrm{A}: \mathrm{B}$ & $\mathrm{A}$ & $\mathrm{B}$ & $\mathrm{A}: \mathrm{B}$ \\
\hline $07.00-08.00$ & 196 & 450 & 43.56 & 217 & 450 & 48.22 \\
\hline $08.00-09.00$ & 285 & 450 & 63.33 & 356 & 450 & 79.11 \\
\hline $09.00-10.00$ & 321 & 450 & 71.33 & 344 & 450 & 76.44 \\
\hline $10.00-11.00$ & 393 & 450 & 87.33 & 455 & 450 & 101,11 \\
\hline $11.00-12.00$ & 441 & 450 & 98.00 & 459 & 450 & 102,00 \\
\hline $12.00-13.00$ & 427 & 450 & 94.89 & 441 & 450 & 98.00 \\
\hline $13.00-14.00$ & 415 & 450 & 92.22 & 438 & 450 & 97.33 \\
\hline $14.00-15.00$ & 376 & 450 & 83.56 & 420 & 450 & 93.33 \\
\hline $15.00-16.00$ & 215 & 450 & 47.78 & 224 & 450 & 49.78 \\
\hline $16.00-17.00$ & 132 & 450 & 29.33 & 167 & 450 & 37.11 \\
\hline
\end{tabular}

Tabel 15. Indeks Mobil

\begin{tabular}{ccccccc}
\hline & \multicolumn{3}{c}{ hari senin } & \multicolumn{3}{c}{ hari minggu } \\
\cline { 2 - 7 } waktu & Akumulasi & $\begin{array}{c}\text { Petak } \\
\text { Parkir }\end{array}$ & Indeks(\%) & Akumulasi & $\begin{array}{c}\text { Petak } \\
\text { Parkir }\end{array}$ & Indeks(\%) \\
\cline { 2 - 7 } & $\mathrm{A}$ & $\mathrm{B}$ & $\mathrm{A}: \mathrm{B}$ & $\mathrm{A}$ & $\mathrm{B}$ & A:B \\
\hline $07.00-0.008$ & 43 & 100 & 43.00 & 56 & 100 & 56.00 \\
\hline $08.00-09.00$ & 69 & 100 & 69.00 & 72 & 100 & 72.00 \\
\hline $09.00-10.00$ & 88 & 100 & 88.00 & 93 & 100 & 93.00 \\
\hline $10.00-11.00$ & 97 & 100 & 97.00 & 103 & 100 & 103.00 \\
\hline $11.00-12.00$ & 106 & 100 & 106.00 & 115 & 100 & 115.00 \\
\hline $12.00-13.00$ & 93 & 100 & 93.00 & 104 & 100 & 104.00 \\
\hline $13.00-14.00$ & 82 & 100 & 82.00 & 93 & 100 & 93.00 \\
\hline $14.00-15.00$ & 65 & 100 & 65.00 & 84 & 100 & 84.00 \\
\hline $15.00-16.00$ & 52 & 100 & 52.00 & 77 & 100 & 77.00 \\
\hline $16.00-17.00$ & 45 & 100 & 45.00 & 58 & 100 & 58.00 \\
\hline
\end{tabular}

Berdasarkan perhitungan Tabel 15 indeks parkir rata-rata sebesar $106 \%$ pada hari senin dan pada hari minggu indeks parkir rata-rata sebesar $115 \%$. Nilai rata-rata indeks parkir lebih dari $100 \%$ itu artinya bahwa petak parkir di areal tersebut tidak mencukupi kebutuhan parkir mobil Rata-rata indeks parkir pada hari minggu lebih tinggi dibandingkan pada hari senin, hal itu disebabkan akumulasi parkir pada hari minggu rata-rata lebih besar. Sedangkan tingginya akumulasi parkir kemungkinan disebabkan tingginya mayoritas masyarakat yang keluar pada hari libur pekan.

\section{e. Durasi Parkir}

Tabel 16 Durasi Parkir Kendaraan

\begin{tabular}{ccc}
\hline kendaraan & senin & minggu \\
\hline motor & $1115: 15: 00$ & $1235: 30: 00$ \\
\hline mobil & $1265: 45: 00$ & $2455: 20: 00$
\end{tabular}


Tabel 17. Rata-Rata Parkir Kendaraan

\begin{tabular}{lllllll}
\hline \multirow{2}{*}{ Hari } & \multicolumn{2}{c}{ Durasi Kendaraan (Menit) } & \multicolumn{2}{c}{$\begin{array}{c}\text { Jumlah } \\
\text { Kendaraan }\end{array}$} & \multicolumn{2}{c}{$\begin{array}{c}\text { Durasi Rata-Rata } \\
\text { Parkir }\end{array}$} \\
\cline { 2 - 7 } & Motor & Mobil & Motor & Mobil & Motor & Mobil \\
\hline Senin & $1115: 15: 00$ & $1265: 45: 00$ & 3422 & 995 & $35: 00$ & $7: 23: 00$ \\
\hline Minggu & $1235: 30: 00$ & $2455: 20: 00$ & 3805 & 1232 & $24: 00$ & $4: 05: 00$ \\
\hline
\end{tabular}

Rata-rata durasi parkir terlama hari minggu dengan kendaraan motor 35 detik dan untuk mobil durasi parlir terlama pada hari minggu 7:23:00 menit.

\section{f. Perhitungan Kebutuhan Ruang Parkir}

Setelah nilai pergantian parkir dan Durasi, serta jumlah akumulasi kendaraan diketahui, maka nilai keseluruhan kebutuhan ruang parkir pada kawasan penelitian dapat diketahui.

Berdasarkan hasil pengukuran survei geometri dapat dihitung ruang parkir yang tersedia, dan perbandingannya terhadap kebutuhan. Menurut Keputusan Direktorat Jenderal Perhubungan Darat No. 272/105/DRJD96, tentang Pedoman Teknis Penyelenggaraan Fasilitas Parkir Direktur Jenderal Perhubungan Darat.

Jadi, Satuan Ruang Parkir (SRP) yang digunakan untuk masing-masing kendaraan adalah sebagai berikut :

- Untuk mobil SRP yang digunakan adalah 2,5 x $5 \mathrm{~m}$

- Untuk sepeda motor SRP yang digunakan adalah $0,75 \times 2 \mathrm{~m}$

Kebutuhan Ruang Parkir

Jumlah kendaraan :

Mobil $=957$

Sepeda Motor $=3842$

Total $=4799$

a. Nilai \% kendaraan :

- Motor $=$

$\frac{3842}{4799} \times 100=80,05 \%$

- $\quad$ Mobil $=$

$\frac{957}{4799} \times 100=19,94 \%$

b. Pembagian panjang ruas parkir terhadap \% kendaraan, dengan panjang ruas parkir $715 \mathrm{~m}$.

Sepeda Motor $=80,05 \%$ x $715=572,35$

Mobil $=19,94 \%$ x $715=142,57$

c. Mencari luas efektif kendaraan parkir.

- Luas efektif

Luas efekif Motor

$572,35 \times 0,75=429 \mathrm{~m}^{2}$
- Luas efekif Mobil

$142 \times 5=710 \mathrm{~m}^{2}$

d. Mencari kebutuhan luas ruang parkir

Untuk motor

- Kebutuhan luas ruang parkir motor pada jam puncak hari senin

$$
\begin{aligned}
\mathrm{KRP} & =\mathrm{VP} \times \mathrm{SRP} \\
& =441 \times 1,5 \\
& =661,5 \mathrm{~m}^{2}
\end{aligned}
$$

- Kebutuhan luas ruang parkir motor pada jam puncak hari minggu

$$
\begin{aligned}
\mathrm{KRP} & =\mathrm{VP} \times \mathrm{SRP} \\
& =459 \times 1,5 \\
& =688,5 \mathrm{~m}^{2}
\end{aligned}
$$

Untuk mobil

- Kebutuhan luas ruang parkir motor pada jam puncak hari senin

$$
\begin{aligned}
\mathrm{KRP} & =\mathrm{VP} \times \mathrm{SRP} \\
& =111 \times 12,5 \\
& =1387 \mathrm{~m}^{2}
\end{aligned}
$$

- Kebutuhan luas ruang parkir motor pada jam puncak hari minggu

$$
\begin{aligned}
\mathrm{KRP} & =\mathrm{VP} \times \mathrm{SRP} \\
& =115 \times 12,5 \\
& =1437 \mathrm{~m}^{2}
\end{aligned}
$$

e. Menentukan jumlah ruang parkir kendaraan

- Untuk Mobil :

$\mathrm{N}=\frac{K R P}{B}$

Keterangan :

$\mathrm{N}=$ Jumlah Petak Parkir,

$\mathrm{KRP}=$ kebutuhan ruang parkir

$\mathrm{B} \quad=\mathrm{SRP}$ (golongan 1$)$

$\mathrm{N}=\frac{1437}{11,5}=125$ ruang

- Untuk Motor :

$\mathrm{N}=\frac{K R P}{B}$

Keterangan :

$\mathrm{N}=$ Jumlah Petak Parkir,

$\mathrm{KRP}=$ kebutuhan ruang parkir

$\mathrm{B}=\mathrm{SRP}$ (golongan 1)

$\mathrm{N}=\frac{668,5}{1,5}=454$ ruang

Dari analisis didapat Kebutuhan luas Ruang Parkir pada jalan mangunsarkoro adalah $688,5 \mathrm{~m}^{2}$ untuk sepeda motor sedangkan untuk mobil $1437 \mathrm{~m}^{2}$. Jadi 
areal parkir jalan mangunsarkoro yang memiliki luas parkir sepeda motor sebesar $429 \mathrm{~m}^{2}$ dan mobil sebesar $710 \mathrm{~m}^{2}$ tidak bisa menampung kendaraan pada jam puncak. Dan juga hasil kebutuhan ruang parkir yang di dapat yaitu untuk motor 454 ruang, untuk mobil di dapat 125 ruang.

\section{KESIMPULAN}

Kesimpulan yang bisa ditarik dari analisis data yang dilakukan pada pembahasan sebelumnya adalah :

1. Melihat hasil Indeks Parkir pada tiap titiknya dapat ditarik kesimpulan bahwa kebutuhan ruang parkir pada lokasi studi secara keseluruhan dapat dipenuhi, juga memiliki kelebihan ruang yang digunakan untuk mengantisipasi perkembangan kendaraan. Hanya ada beberapa waktu yang mengalami over kapasitas $(>100 \%)$, dalam pelaksanaan dilapangan diharapkan waktu yang mengalami over kapasitas diatas dapat dialihkan kepada waktu-waktu yang lain.

2. Berdasarkan hasil yang diperoleh kebutuhan Ruang Parkir jalan mangun sarkoro kebutuhan ruang parkir yang di dapat yaitu untuk motor 454 ruang, untuk mobil di dapat 125 ruang.

\section{DAFTAR PUSTAKA}

Anonim, 1993, Peraturan Pemerintah Nomor 43 tahun 1993 Tentang Prasarana dan Lalu Lintas Jalan

Departemen Perhubungan Direktur Jenderal Perhubungan Darat,1993. Penyele nggaraan Fasilitas Parkir,

Departemen Perhubungan Direktur Jenderal Perhubungan Darat , 1993.Rancangan Pedoman Teknis Pembangunan dan Penyelenggaraan Angkutan Penumpang dan Barang ) 